\title{
Stroke Vignette
}

\section{Cerebrovascular Diseases}

Magnetic Resonance Angiography Detection of Four Asymptomatic Intracranial Aneurysms. A 40-year-old healthy woman underwent screening for the presence of intracranial aneurysms. Her sister recently had a subarachnoid haemorrhage at the age of 42. Sixty years previously her grandmother had an intracranial haemor- rhage of unknown cause also at the age of 42 . Magnetic resonance angiography (fig. 1) showed four aneurysms (arrows): two at the right middle cerebral artery (A and $\mathrm{B}, 4 \mathrm{~mm}$ each), a third at the basilar top $(\mathrm{C}, 3 \mathrm{~mm})$ and a fourth at the left middle cerebral artery $(\mathrm{D}, 6 \mathrm{~mm})$. Cerebral angiography confirmed the presence of all aneurysms (fig. 2-4). To prevent subarachnoid haemorrhage all aneurysms were operated on without complications.

\section{Raaymakers, P. Buijs}

Departments of Neurology and Radiology, University Hospital Utrecht, The Netherlands

1

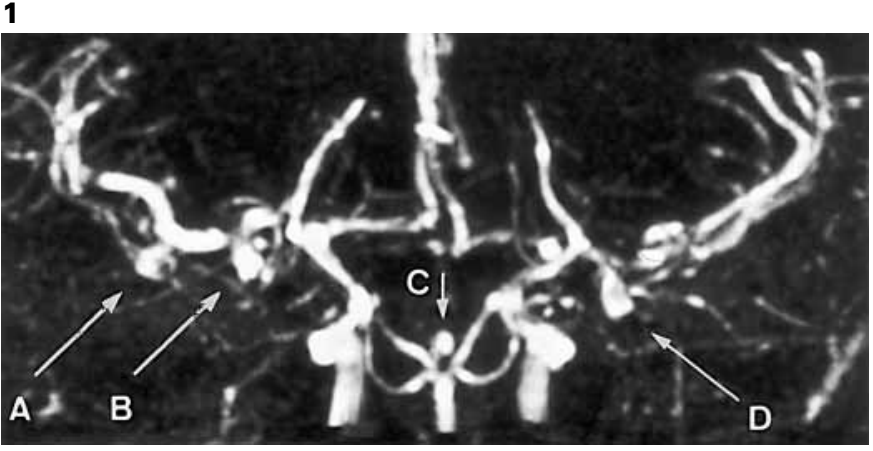

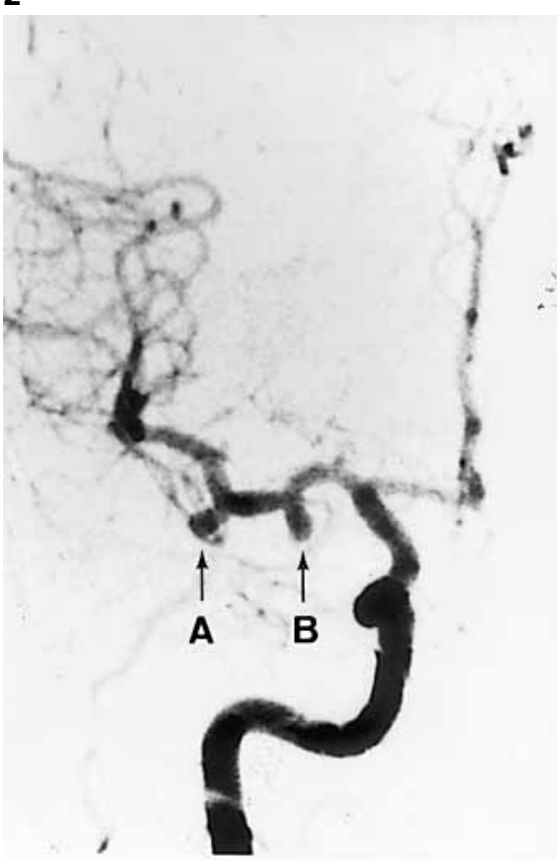

3

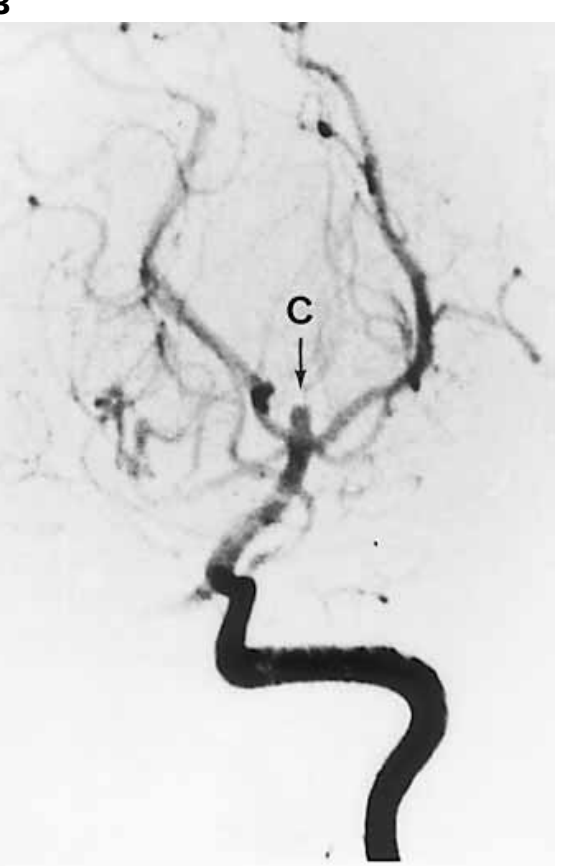

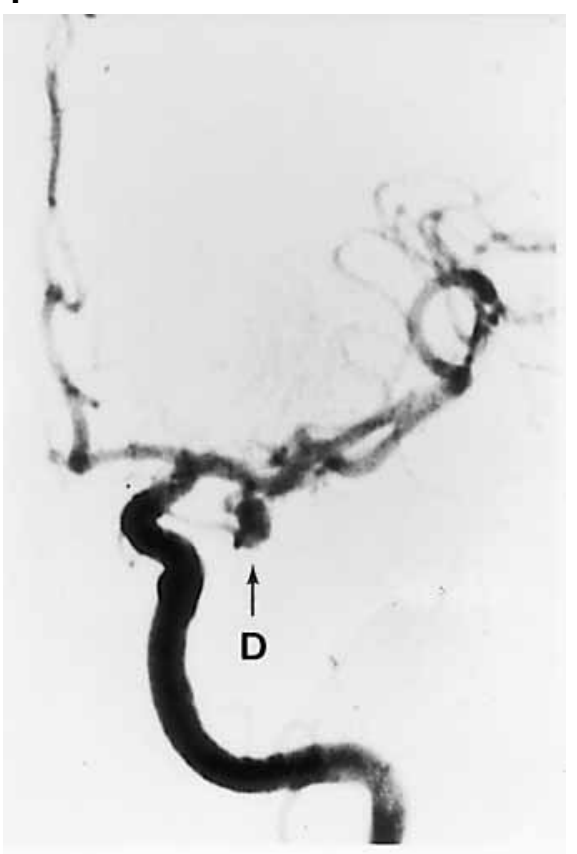

\section{KARGER}

๑๐ 1998 S. Karger AG, Basel

Fax + 41613061234

E-Mail karger@karger.ch

www. karger.com
This article is also accessible online at: http://BioMedNet.com/karger 